\title{
Evaluation of Skin-mounted Sensor for Head Impact Measurement
}

\author{
Stephen Tiernan \\ Technological University Dublin, stephen.tiernan@tudublin.ie \\ Gary Byrne \\ Technological University Dublin \\ David Michael O'Sullivan \\ Division of Sport Science, Pusan National University, Busan, Republic of Korea, \\ davidosullivan@pusan.ac.kr
}

Follow this and additional works at: https://arrow.tudublin.ie/ittengart

Part of the Engineering Commons

\section{Recommended Citation}

O'Sullivan, D.M. (2019)Evaluation of skin-mounted sensor for head impact measurement, $J$ Engineering in Medicine 1-10, DOI: 10.1177/0954411919850961

This Article is brought to you for free and open access by the School of Engineering at ARROW@TU Dublin. It has been accepted for inclusion in Articles by an authorized administrator of ARROW@TU Dublin. For more information, please contact arrow.admin@tudublin.ie, aisling.coyne@tudublin.ie,gerard.connolly@tudublin.ie.

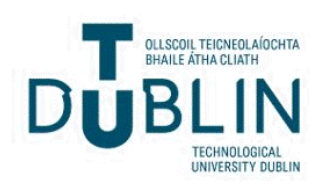




\section{Evaluation of skin-mounted sensor for head impact measurement}

Proc IMechE Part H:

$\mathrm{J}$ Engineering in Medicine

$\mathrm{I}-10$

(c) IMechE 2019

Article reuse guidelines:

sagepub.com/journals-permissions DOI: 10.1 177/095441191985096 journals.sagepub.com/home/pih (S)AGE

\author{
Stephen Tiernan' ${ }^{(D,}$, Gary Byrne' and David Michael O'Sullivan²
}

\begin{abstract}
The requirement to measure the number and severity of head impacts in sports has led to the development of many wearable sensors. The objective of this study was to determine the reliability and accuracy of a wearable head impact sensor: xPatch, X2Biosystems, Inc. The skin-mounted sensor, xPatch, was fixed onto a Hybrid III headform and dropped using an impact test rig. A total of 400 impacts were performed, ranging from $20 \mathrm{~g}$ to $200 \mathrm{~g}$ linear acceleration, and impact velocities of $1.2-3.9 \mathrm{~m} / \mathrm{s}$. During each impact, the peak linear acceleration, angular velocity and angular acceleration were recorded and compared to the reference calibrated data. Impacts were also recorded using a high-speed video camera. The results show that the linear acceleration recorded by the xPatch during frontal and side impacts had errors of up to $24 \%$ when compared to the referenced data. The angular velocity and angular acceleration had substantially larger errors of up to $47.5 \%$ and $57 \%$, respectively. The location of the impact had a significant effect on the results: if the impact was to the side of the head, the device on that side may have an error of up to $71 \%$, thus highlighting the importance of device location. All impacts were recorded using two separate xPatches and, in certain cases, the difference in angular velocity between the devices was $43 \%$. In conclusion, the xPatch can be useful for identifying impacts and recording linear accelerations during front and side impacts, but the rotational velocity and acceleration data need to be interpreted with caution.
\end{abstract}

\title{
Keywords
}

xPatch, head impact sensor, head acceleration

Date received: 2 October 2018; accepted: 23 April 2019

\section{Introduction}

Concussion in sport is very prevalent, with between 1.6 and 3.8 million sports-related concussions in the United States each year. ${ }^{1}$ The diagnosis of concussion is particularly difficult with many studies reporting that approximately $50 \%$ of concussions go unreported. ${ }^{2,3}$ The 5th international conference on concussion in sport defined concussion as a complex pathophysiological process affecting the brain, induced by biomechanical forces. ${ }^{4}$ These biomechanical forces may be induced from a combination of direct and indirect head impacts, causing both linear and rotational motions. ${ }^{5}$ Abel et al. ${ }^{6}$ conducted research in 1978, using monkeys, to investigate the effects of head and brain motion during impacts; they concluded that rotational acceleration in particular was linked to concussive injuries. Furthermore, they stated that, following an impact, rotational motion is the primary cause of strain in brain tissue. Research has since validated this theory in terms of human injuries. ${ }^{7-9}$ In addition, the magnitude of strain, which the brain undergoes during an impact, has been determined to be dependent on both the magnitude of the impact and the impact location. ${ }^{10-13}$

In 2003, the first wireless impact sensor was developed to measure the severity of impacts in American football. ${ }^{14}$ The Head Impact Telemetry System (HITS) sensor, developed by Simbex, Inc., is an array of six or nine accelerometers embedded in a football helmet. Its accuracy has been investigated by various groups and determined to be dependent on the fit of the helmet to the head. ${ }^{15,16}$ It has been used in numerous American football studies ${ }^{17,18}$ and also in boxing. ${ }^{19}$ Due to the fact that not all contact sports utilise a helmet for protection, other wireless sensors have been developed,

\footnotetext{
'Technological University Dublin, Dublin, Ireland

${ }^{2}$ Division of Sport Science, Pusan National University, Busan, Republic of Korea
}

\section{Corresponding author:}

David Michael O'Sullivan, Division of Sport Science, Pusan National

University, 2, Busandaehak-ro 63 beon-gil, Geumjeong-gu, Busan 4624I, Republic of Korea.

Email: davidosullivan@pusan.ac.kr 
such as instrumented mouthguards (X2Biosystems, Inc.), headbands (Sim-G; Triax Technologies, Inc. ${ }^{20}$ and skin patches (xPatch; X2Biosystems, Inc.). These have been used in studies of head impacts in unhelmeted sports such as soccer ${ }^{21,22}$ and rugby. ${ }^{23}$

To date, the majority of studies on the accuracy of head impact sensors have used a Hybrid III headform $^{24,25}$ fitted with a reference a triaxial linear accelerometer and a triaxial gyroscope positioned at the centre of gravity. The Hybrid III dummy headform has a viscoelastic skin, the response of which is strain independent up to strains of $20 \%{ }^{26}$ In a recently published study, helmet-mounted and head-mounted acceleration sensors were tested. ${ }^{25}$ The study used a Hybrid III headform fitted with a Riddell helmet, and data were collected from a number of sensors, including the HITS and the xPatch. The results found that the xPatch peak linear acceleration (PLA) errors ranged from 7.7\% to $57.9 \%$, while peak angular acceleration (PAA) errors ranged from $9.5 \%$ to $245.6 \%$. This study utilised an impulse hammer and impacted the head in seven locations, where the majority of impacts were below $80 \mathrm{~g}$ (PLA). A study by Schussler et al. ${ }^{27}$ in 2017 on the accuracy of the xPatch found PLA errors of up to $31 \%$ and PAA errors up to $23.4 \%$; this study impacted a Hybrid III head fitted with a lacrosse helmet. Despite these errors and unlike other studies, they concluded that the xPatch device measurements highly correlated with their reference device.

Rowson et al. ${ }^{18}$ used the xPatch to record 8999 head impacts in women's collegiate soccer, and only 1703 of these could be confirmed by video analysis, thus resulting in a positive prediction rate of only $16.3 \%$. One of the few studies on the accuracy of the xPatch using an unhelmeted headform was undertaken by Nevins et al. in 2015. Their study was limited in that they only impacted the head in two frontal locations using three types of soft balls; they found that the xPatch had errors of approximately $25 \%$ for PLA and underpredicted PAA by $25 \%-35 \%{ }^{28}$

Unhelmeted impacts are quite different to helmeted impacts as the acceleration pulses are of a short duration and contain higher frequency components. This study addresses a number of issues not addressed in the other studies: how does the xPatch sensor perform in unhelmeted impacts above $80 \mathrm{~g}$; how does it perform during impacts to the side and rear of the headform; how does the device's output compare when fitted to the left-hand side (LHS) and right-hand side (RHS) of the head. Unlike other investigations, this study investigated the accuracy of the device over its full range $(20 \mathrm{~g}-$ $200 \mathrm{~g}$ ) following impacts in four directions to an unhelmeted head.

\section{Methods}

This study tested the accuracy and repeatability of the xPatch sensor developed by X2Biosystems. The sensor is a six-degree-of-freedom measurement device, consisting of three single-axis accelerometers and three angular rate sensors. The device measures $37 \mathrm{~mm}$ by $14 \mathrm{~mm}$ and is designed to attach to the skin over the mastoid process (behind the ear) of the athlete. During an impact, linear acceleration in $x, y$ and $z$ is recorded, as well as rotational velocity about the three axes. Data are recorded by the device for $100 \mathrm{~ms}$ with the sampling rates of 1000 and $800 \mathrm{~Hz}$ for linear acceleration and angular velocity, respectively. The acceleration data are transformed to calculate linear acceleration at the centre of gravity of the head. Rotational acceleration is calculated from rotational velocity using five-point differentiation. Both the transformation and differentiation were carried using the software supplied by X2Biosystems. The equations for the transformation and differentiation are unavailable to the user, as they are embedded in the software. The transformation is based on equation (1) (below), where $a_{C G}$ is the linear acceleration at the centre of gravity of the head, $a_{P}$ is the linear acceleration recorded by the device, $\omega$ and $\alpha$ are the angular velocity and acceleration of the head, respectively, and $r_{p-C G}$ is the geometric relationship between the device and the centre of gravity of the head $^{27}$

$$
a_{C G}=a_{P}+\left(\alpha \times r_{p-C G}\right)+\omega\left(\omega \times r_{p-C G}\right)
$$

Two xPatches were fixed according to the manufacturer's instructions, to a 50th percentile Hybrid III dummy headform. The xPatches were attached using the manufacturer's adhesive patches, to the left and right sides of the head, in the area of the mastoid part of the temporal bone as recommended by X2Biosystems, Inc.: $72 \mathrm{~mm}$ from the head's centre of gravity to the inside edge of the xPatch (Figure 1).

Reference devices consisting of a triaxial linear accelerometer (Kistler 8688A) and three angular rate sensors (DTS ARS12K) were mounted at the centre of gravity of the headform on a block supplied by the manufacturer (Humanetics, Inc.). The reference data were sampled at $10,000 \mathrm{~Hz}$, and $200 \mathrm{~ms}$ of data were recorded per impact. Linear acceleration was filtered at $1000 \mathrm{~Hz}$ and rotational velocity was filtered at $300 \mathrm{~Hz}$. Fast Fourier transformation within LabVIEW (National Instruments) ${ }^{29}$ was used to calculate the amplitude spectrum and verify these as suitable frequencies, that is, no loss of data. A forward finite difference method was computed to determine rotational acceleration (equation (2)). All reference data were recorded using a customised LabVIEW 2015 program

$$
f^{\prime}(x)=\frac{f(x+5 h)-f(x)}{5 h}
$$

Impacts were created by allowing the headform to drop in a purpose-built drop test rig and impact a steel hemispherical anvil of $0.12 \mathrm{~m}$ diameter (Figure 1). As skull fracture is not being investigated, the diameter of this impactor is not considered significant. A wide variety 


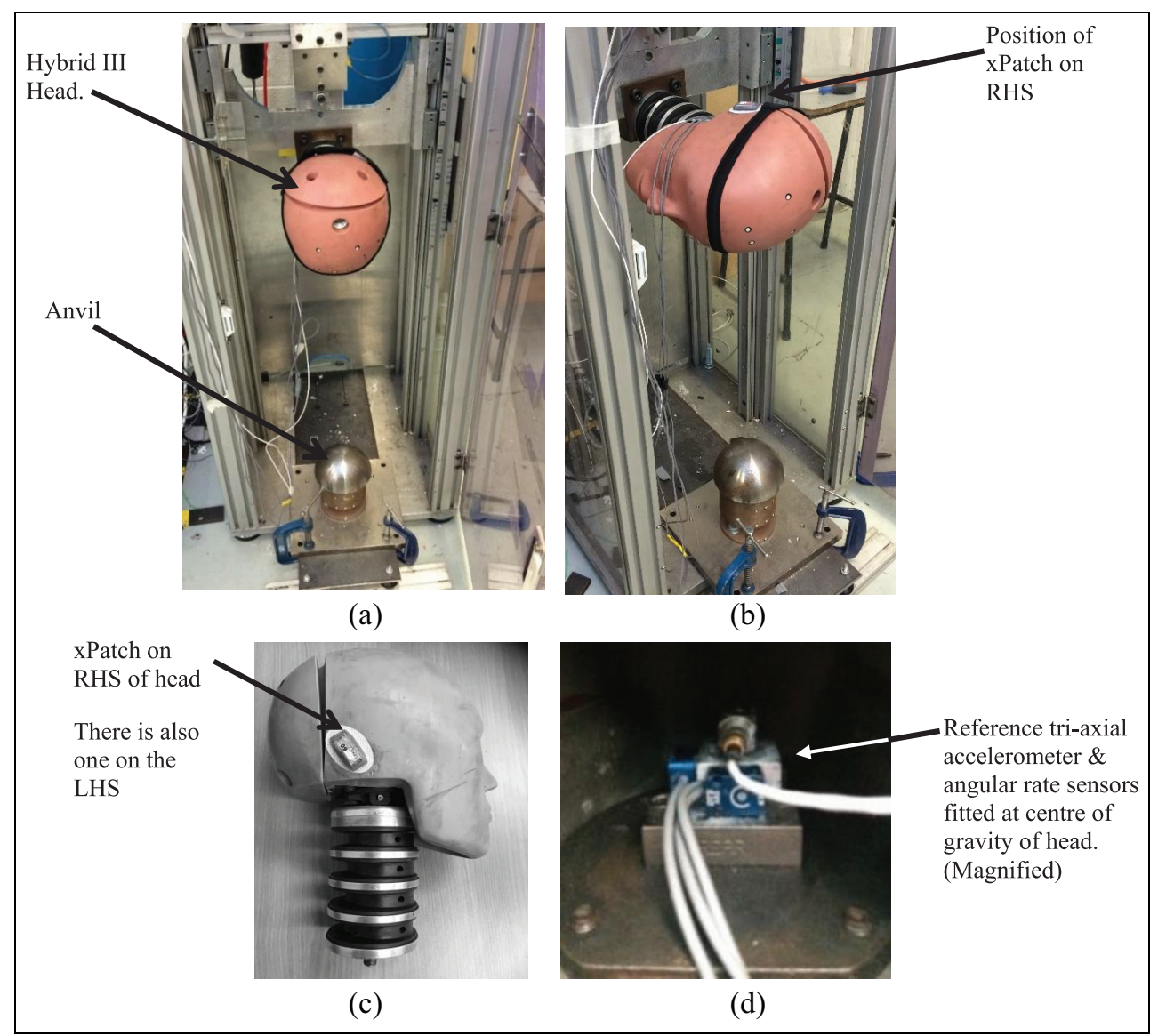

Figure I. (a) Drop test rig (view I), (b) drop test rig (view 2), (c) drop Hybrid III head with xPatch attached and (d) reference sensors.

of impactors have been used in previous studies. $^{25,27,28,30}$ The Hybrid III head was rigidly attached to the cross bar of the apparatus, and this cross bar was constrained so as to allow only vertical movement. This constraint ensured consistency in the repeatability of the tests (sample results in Table 1). Following an impact, the rotation of the head is a function of the stiffness of the neck, as the base of the neck is rigidly constrained in the vertical direction.

The test conditions were designed to cover the sensors' full linear acceleration range of $20 \mathrm{~g}-200 \mathrm{~g}$; this corresponded to the drop heights of $160-610 \mathrm{~mm}$. The testing procedure consisted of a total of 10 drop heights, and each test was repeated 10 times. Impacts were to four locations: left side, right side, front and rear of the head (Figure 2). Thus, a total of 400 tests were conducted. A sample of the linear acceleration results from a drop of $360 \mathrm{~mm}$ is shown in Figure 3, and the duration of the impact in this case is $12.5 \mathrm{~ms}$.

A sample of the results from a front drop height of $360 \mathrm{~mm}$ is shown in Table 1, the PLA average was $62.83 \mathrm{~g}$ (standard deviation $(\mathrm{SD})=1.80$ ), rotational velocity is $20.07 \mathrm{rad} / \mathrm{s}(\mathrm{SD}=1.62)$ and the average calculated rotational acceleration was $5135.82 \mathrm{rad} / \mathrm{s}$ $(\mathrm{SD}=1062)$.

This study was exempt from institutional review board (IRB) approval as it did not involve human participants as outlined by the code of federal regulations (45 CFR 46.102(f)).

\section{Results}

\section{Linear acceleration}

An analysis of the data found that all the impacts were recorded by the xPatch, that is, no missing impacts (Table 2). Pearson's correlation coefficient and predicted residual error sum of squares (PRESS) statistic were calculated to investigate the reliability of the data and to provide a summary measure of fit of the model to the data.

The correct location (left, right, front and rear) of the impact was also recorded by both xPatches. When impacted in the front, the linear acceleration of the xPatch device correlated well with the reference accelerometer: $R^{2}=0.9527$; PRESS statistic $=5403$ for the LHS and $R^{2}=0.9471$; PRESS statistic $=5403$ for the RHS (see Figure 4).

The xPatch overestimated the linear acceleration during a frontal impact. This overestimation was on average $16.9 \%$ for the LHS xPatch and $23.7 \%$ for the RHS xPatch (Figure 5).

The linear acceleration for the RHS and LHS impacts had a poorer correlation than the frontal impacts. The xPatch device on the side that was being 
Table I. Sample results from 10 repeated impacts to the front (forehead) of the headform.

\begin{tabular}{|c|c|c|c|c|c|c|c|c|c|c|}
\hline \multirow[t]{2}{*}{ No. } & \multirow[t]{2}{*}{ Test time } & \multicolumn{3}{|c|}{ Reference sensors } & \multicolumn{3}{|c|}{ xPatch LHS } & \multicolumn{3}{|c|}{ xPatch RHS } \\
\hline & & $\begin{array}{l}\text { Linear } \\
\text { Accel. (g) }\end{array}$ & $\begin{array}{l}\text { Rot. Velocity } \\
\text { (rad/s) }\end{array}$ & $\begin{array}{l}\text { Rot. Accel. } \\
(\mathrm{rad} / \mathrm{s})\end{array}$ & $\begin{array}{l}\text { Linear } \\
\text { Accel. (g) }\end{array}$ & $\begin{array}{l}\text { Rot. Velocity } \\
\text { (rad/s) }\end{array}$ & $\begin{array}{l}\text { Rot. } \\
\text { Accel. } \\
\text { (rad/s) }\end{array}$ & $\begin{array}{l}\text { Linear } \\
\text { Accel. (g) }\end{array}$ & $\begin{array}{l}\text { Rot. } \\
\text { Velocity } \\
\text { (rad/s) }\end{array}$ & $\begin{array}{l}\text { Rot. } \\
\text { Accel. } \\
\text { (rad/s) }\end{array}$ \\
\hline 1.0 & $\mid 4: 30$ & 65.58 & 19.42 & 4866.1 & 79.45 & 23.64 & 4395.0 & 79.33 & 17.33 & 4008.0 \\
\hline 2.0 & |4:33 & 63.74 & 22.08 & 4028.0 & 77.00 & 23.80 & 4356.9 & 77.44 & 17.69 & 4151.5 \\
\hline 3.0 & 14:36 & 61.70 & 19.80 & 3668.2 & 79.88 & 24.14 & 4629.7 & 85.00 & 27.41 & 4242.7 \\
\hline 4.0 & $14: 39$ & 61.23 & 21.46 & 5653.6 & 75.00 & 23.85 & 4435.6 & 77.95 & 21.45 & 4060.0 \\
\hline 5.0 & | 4:42 & 67.03 & 21.20 & 6106.2 & 77.04 & 23.49 & 4445.7 & 82.03 & 18.29 & 3943.8 \\
\hline 6.0 & | 4:45 & 60.37 & 19.08 & 4724.1 & 77.43 & 24.35 & 4609.0 & 84.48 & 28.54 & 4330.4 \\
\hline 7.0 & |4:48 & 60.7I & 20.16 & 7026.2 & 78.62 & 24.57 & 4667.9 & 82.38 & 26.30 & 4319.6 \\
\hline 8.0 & $|4: 5|$ & 62.44 & 19.37 & 6496.6 & 80.7I & 24.36 & 4601.4 & 83.49 & 25.22 & 4256.4 \\
\hline 9.0 & $\mid 4: 54$ & 62.84 & 16.28 & 4366.2 & 77.70 & 23.26 & 4243.0 & 85.23 & 26.27 & 3879.2 \\
\hline 10.0 & $14: 59$ & 62.70 & 21.84 & 4423.0 & 78.02 & 24.52 & 4636.1 & 82.72 & 24.20 & 4369.3 \\
\hline \multicolumn{2}{|c|}{$\begin{array}{l}\text { Standard } \\
\text { deviation }\end{array}$} & 2.01 & 1.63 & 1065.8 & 1.57 & 0.43 & 137.9 & 2.70 & 4.03 & 165.25 \\
\hline \multicolumn{2}{|c|}{ Average } & 62.83 & 20.07 & 5135.8 & 78.08 & 24.00 & 4502.0 & 82.01 & 23.27 & $4 \mid 56.1$ \\
\hline
\end{tabular}

LHS: left-hand side; RHS: right-hand side.

Drop height was $360 \mathrm{~mm}$. Linear acceleration, rotational velocity and calculated rotational accelerations are given for the reference sensors and the xPatches fixed to the LHS and RHS of the headform.

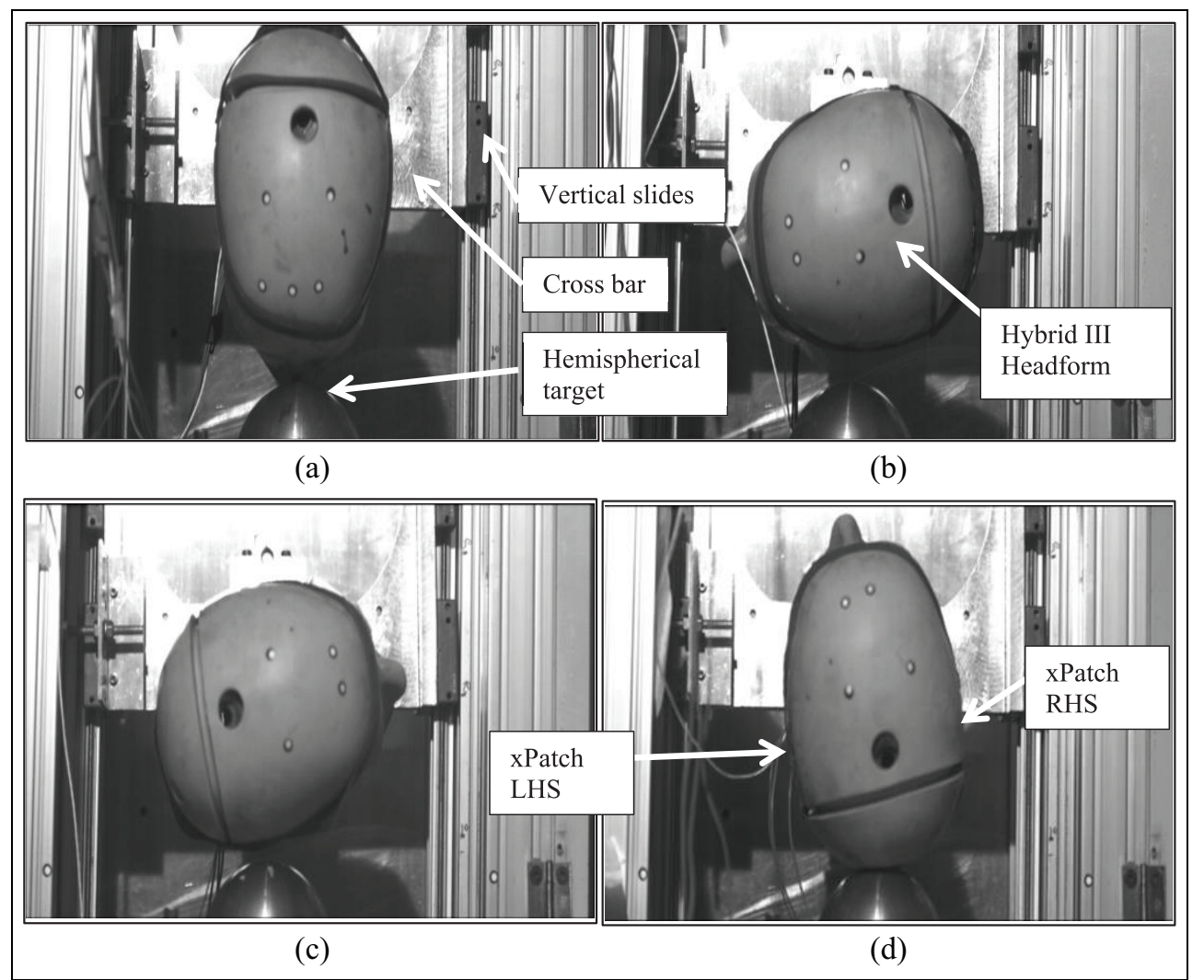

Figure 2. Sample drop from $360 \mathrm{~mm}$ to (a) front, (b) left, (c) right and (d) rear. Images were taken from high-speed video of impacts.

impacted overestimated impacts over $110 \mathrm{~g}$ by $9 \%$ and underestimated impacts under $90 \mathrm{~g}$ by $16 \%$. The device on the opposite side to the impact overestimated impacts over $110 \mathrm{~g}$ by $14.5 \%$ and underestimated impacts under $90 \mathrm{~g}$ by $13 \%$. Figures $6-8$ show box plots of the median and interquartile range of the linear acceleration recorded by Kistler reference accelerometer and the xPatch devices on the LHS and RHS of the head.

The results recorded from the rear impact tests had a poor correlation to the reference data $\left(R^{2}\right.$ for LHS $=0.7311, R^{2}$ for RHS $\left.=0.7021\right)$.

Similar to the side impacts, the xPatch overestimated the more severe impacts. The xPatch applied to the 


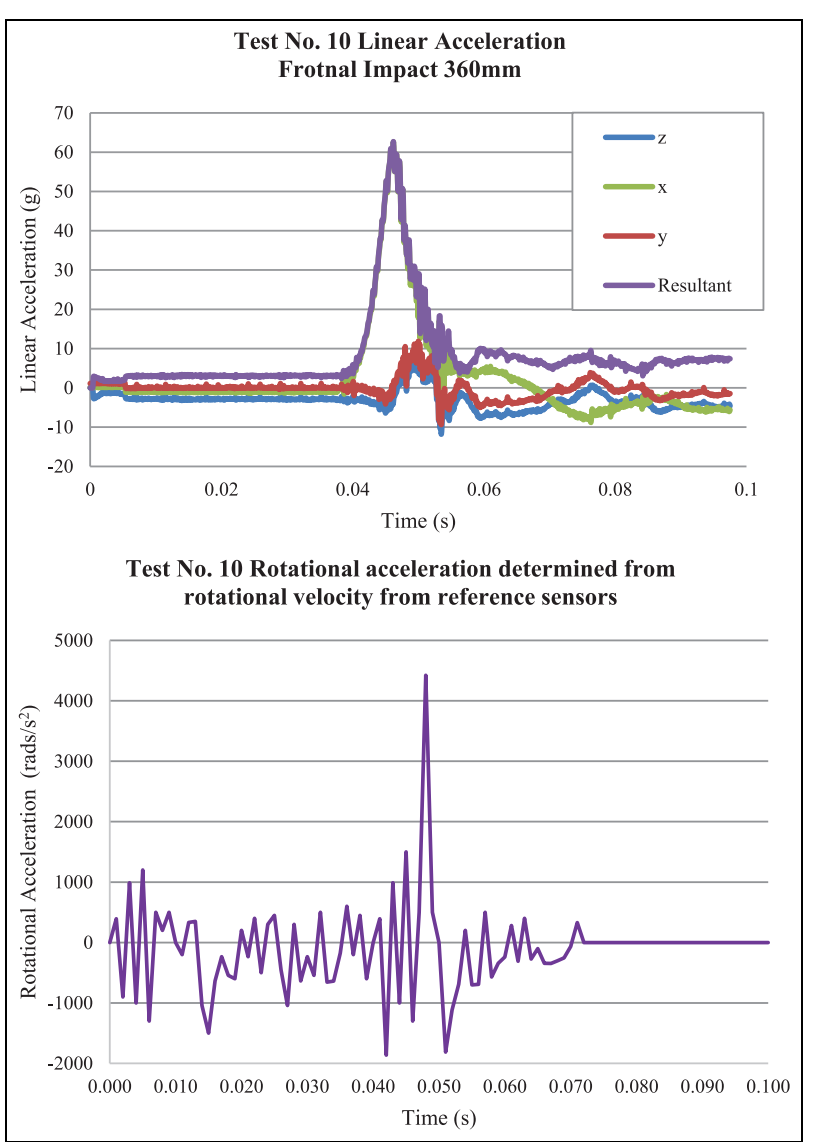

Figure 3. Linear and rotational acceleration following a frontal impact from a drop height of $360 \mathrm{~mm}$ (test no. 10).

LHS of the headform underestimated impacts over $130 \mathrm{~g}$ on average by $5 \%$ and overestimated impacts under $120 \mathrm{~g}$ by $30 \%$, on average. The xPatch applied to the RHS overestimated impacts over $100 g$ by $20 \%$ on average and underestimated impacts under $90 \mathrm{~g}$ by an average of $30 \%$.

\section{Rotational velocity}

It was found that the rotational velocity correlation with the reference device was not as good as that for linear accelerations $\left(R^{2}\right.$ for LHS $=0.7841$; PRESS statistic $=566.5, R^{2}$ for RHS $=0.7805 ;$ PRESS statistic $=$ 549.3). The xPatch overestimated the rotational velocity on average by $17.4 \%$ for the sensor on the LHS of the headform and $13.9 \%$ for the RHS of the headform (see Table 3).

The side impact results revealed a significant difference between the xPatches on the RHS and LHS of the headform, with the device on the opposite side to the impact performing better than the device on the impact side. The device on the side of the impact overestimated the velocity by an average of $47.5 \%$, while the device on the opposite side of the impact overestimated the velocity by $23 \%$.

It can also be found from the xPatch results from the rear impacts that the devices overestimated the angular velocity on average by $20 \%$ for the device on the left of the headform and $33 \%$ for the device on the right. Rear impacts provided the best rotational velocity correlation, with the referenced data $\left(R^{2}\right.$ for LHS $=0.8896$, PRESS statistic $=68 \times 10^{6}$ and $R^{2}=0.7919$ for RHS, PRESS statistic $=72 \times 10^{6}$ ).

\section{Rotational acceleration}

Rotational acceleration produced results that had a poor to medium correlation $\left(R^{2}=0.28-0.88\right)$ with the reference data. The error in the results from the xPatch varied depending on head orientation, xPatch location and impact magnitude. The xPatch underestimated the angular acceleration during frontal impacts with an average error of $14.3 \%$ for the LHS device and $19.6 \%$ for the RHS device; the errors were substantially higher

Table 2. Summary of linear acceleration results for frontal impacts.

\begin{tabular}{|c|c|c|c|c|c|c|c|c|c|c|c|}
\hline \multirow{2}{*}{$\begin{array}{l}\text { Drop } \\
\text { height } \\
(\mathrm{mm})\end{array}$} & \multicolumn{3}{|c|}{ Reference sensors } & \multicolumn{4}{|l|}{ xPatch LHS } & \multicolumn{4}{|c|}{ xPatch RHS } \\
\hline & Average (g) & Std. Dev. & $\begin{array}{l}\text { Standard } \\
\text { error of } \\
\text { mean }\end{array}$ & Average (g) & Std. Dev. & $\begin{array}{l}\text { Standard } \\
\text { error of } \\
\text { mean }\end{array}$ & \%Error & $\begin{array}{l}\text { Average } \\
(\mathrm{g})\end{array}$ & $\begin{array}{l}\text { Std. } \\
\text { Dev. }\end{array}$ & $\begin{array}{l}\text { Standard } \\
\text { error } \\
\text { of mean }\end{array}$ & \%Error \\
\hline 610 & | 27.57 & 11.84 & 3.95 & 129.72 & 5.86 & 1.75 & 1.69 & 133.73 & 0.41 & 1.25 & 4.83 \\
\hline 560 & $|08.8|$ & 4.23 & 1.83 & 115.34 & 3.55 & 0.40 & 6.00 & 125.34 & 0.32 & 0.90 & 15.19 \\
\hline 510 & 97.67 & 2.57 & 0.86 & $108.4 \mid$ & 1.64 & 1.00 & 10.99 & 115.04 & 0.28 & 0.71 & 17.78 \\
\hline 460 & 85.16 & 3.96 & 1.32 & 96.14 & 4.27 & 0.44 & 12.89 & $102.5 \mid$ & 0.26 & 0.64 & 20.37 \\
\hline 410 & 75.41 & 2.56 & 0.85 & 87.71 & 2.98 & 0.54 & 16.31 & 93.49 & 0.48 & 0.37 & 23.98 \\
\hline 360 & 62.83 & 1.80 & 0.60 & 78.08 & 2.48 & 0.50 & 24.27 & 82.01 & 3.51 & 0.85 & 30.51 \\
\hline 310 & 53.41 & 1.15 & 0.47 & 67.41 & 2.07 & 0.39 & 26.21 & 69.99 & 0.26 & 0.37 & 31.03 \\
\hline 260 & 42.85 & 0.41 & 0.17 & 57.02 & 1.68 & 0.40 & 33.06 & 58.24 & 0.36 & 0.42 & 35.91 \\
\hline 210 & 36.42 & 3.08 & 0.00 & 46.87 & 7.14 & 0.45 & 28.70 & 50.85 & 0.23 & 0.58 & 39.64 \\
\hline 160 & 30.86 & 3.64 & 1.50 & 33.51 & 11.11 & 1.14 & 8.59 & 36.17 & 0.28 & 1.29 & 17.22 \\
\hline
\end{tabular}

LHS: left-hand side; RHS: right-hand side.

Results for reference sensors and LHS and RHS xPatches are given as well as percentage errors between the xPatch devices and the reference devices. 


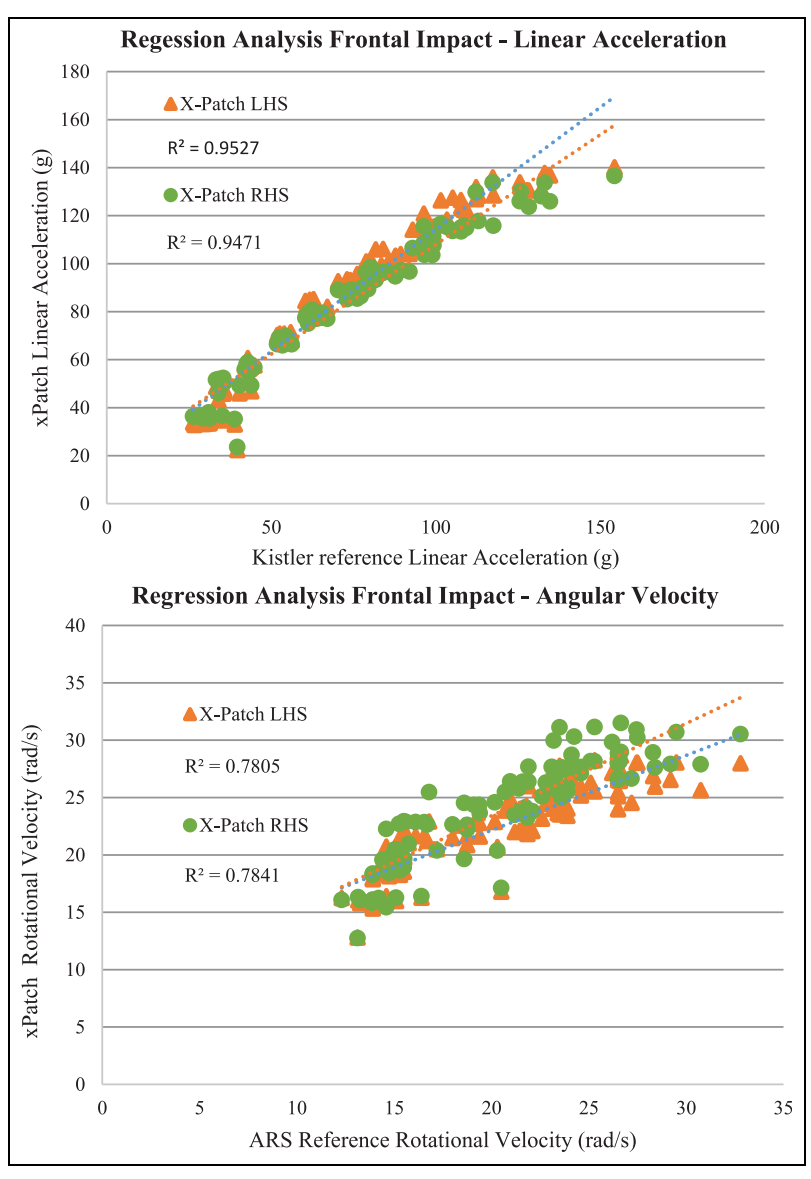

Figure 4. Linear acceleration and rotational velocity regression analysis for frontal impacts. Reference device data are compared to xPatch LHS and RHS data.

for impacts to the side and rear of the headform (see Table 4).

Impacts to the side of the head had an overestimation error of $46.5 \%$ for the device on the impact side and an average underestimation error of $52 \%$ for the device on the opposite side to the impact.

Rear impacts had an error of $-57 \%$ for the LHS xPatch and $12 \%$ for the RHS xPatch. The rotational acceleration from the xPatch had very poor accuracy and consistency when the headform was impacted to the side and rear. The largest error was a $71 \%$ underestimation compared to the reference sensor; this was recorded during impacts to the right side of the headform. The errors for all impacts are summarised in Table 5.

\section{Discussion}

This study assessed the performance of the xPatch sensor in laboratory conditions by comparing the recorded measurements with calibrated reference devices. The results illustrate that the xPatch provides a reasonable indication of linear acceleration during frontal impacts, but with a possible overestimation of up to $18 \%$. This overestimation error was in keeping with $\mathrm{Wu}$ et al.'s ${ }^{31}$ study of low-speed impacts (overestimation of $15 \mathrm{~g}$ ) and

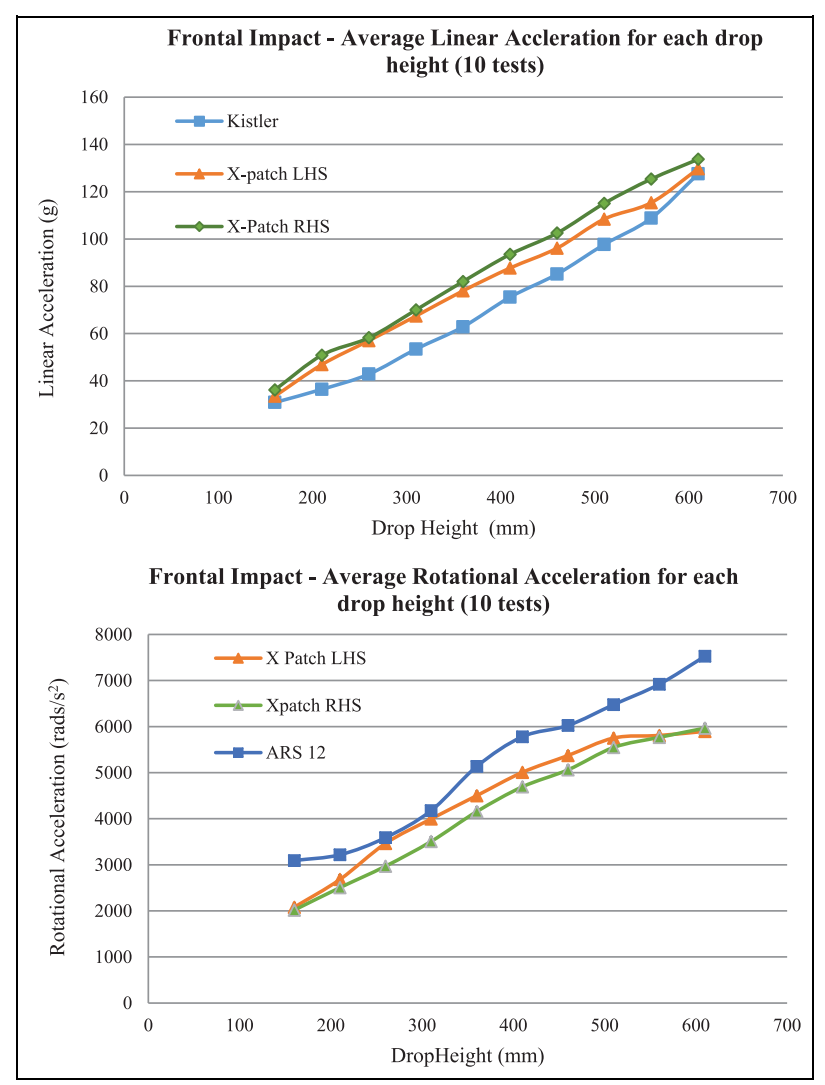

Figure 5. Linear and rotational acceleration following a frontal impact; LHS and RHS xPatch and reference data are shown.

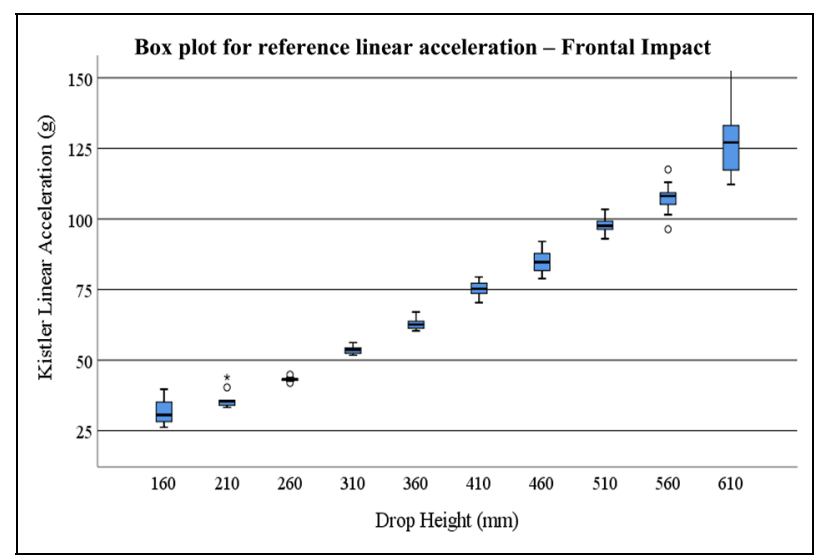

Figure 6. Box plot of median and interquartile range for the linear acceleration recorded by the reference Kistler accelerometer for each drop height.

Schussler et al.'s ${ }^{27}$ study of helmeted impacts (PLA error $22 \%$ ). The rear impacts had errors of up to $30 \%$ and perhaps of greatest concern is the underestimation of severe $(>110 g)$ impacts; this underestimation has not been reported in other studies. Angular velocity errors were large (up to $47.5 \%$ ) and hence the rotational acceleration errors were also large $(57 \%)$, as this is derived from the rotational velocity. This study 


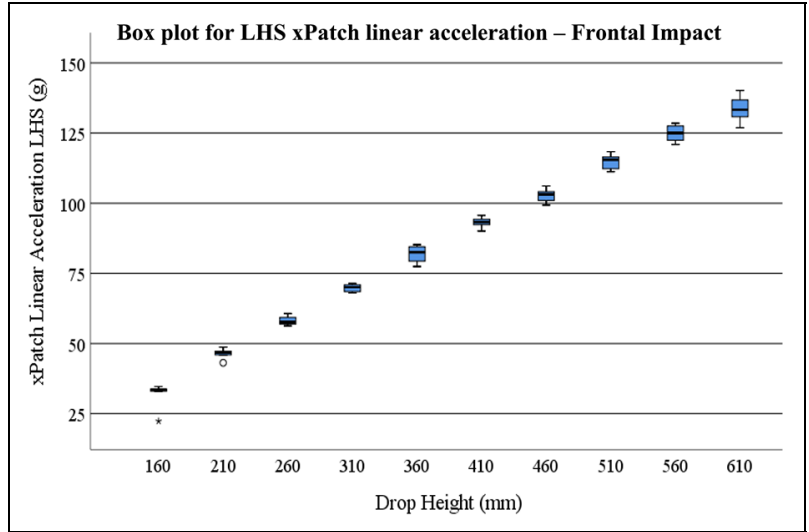

Figure 7. Box plot of median and interquartile range for the linear acceleration recorded by the XPatch on the left-hand side of the headform for each drop height.

found that rotational acceleration was underestimated by the xPatch; this was similar to Nevins et al.' ${ }^{28}$ findings from their study of frontal impacts. Unlike Nevin et al.'s study, this investigation also tested severe frontal, side and rear impacts; these were found to produce substantially higher errors (up to $71 \%$ ). A study by Siegmund et al., ${ }^{32}$ using the xPatch with a helmeted cadaver, reported much larger errors of PLA $(64 \% \pm 41 \%)$ and PAA $(370 \% \pm 456 \%)$; this was not broken down by impact location. The large discrepancy between the xPatch and the reference sensor data in Siegmund et al.' ${ }^{32}$ study may be partly a result of the degree of coupling between the head and the xPatch: when attached to human skin, the device may move up to $4 \mathrm{~mm}$ relative to the skull, even during low impacts.

During the data processing, it was found that the sampling rate of both the reference data and the xPatch data was critical in acquiring accurate results. The xPatch is reported to sample linear acceleration at

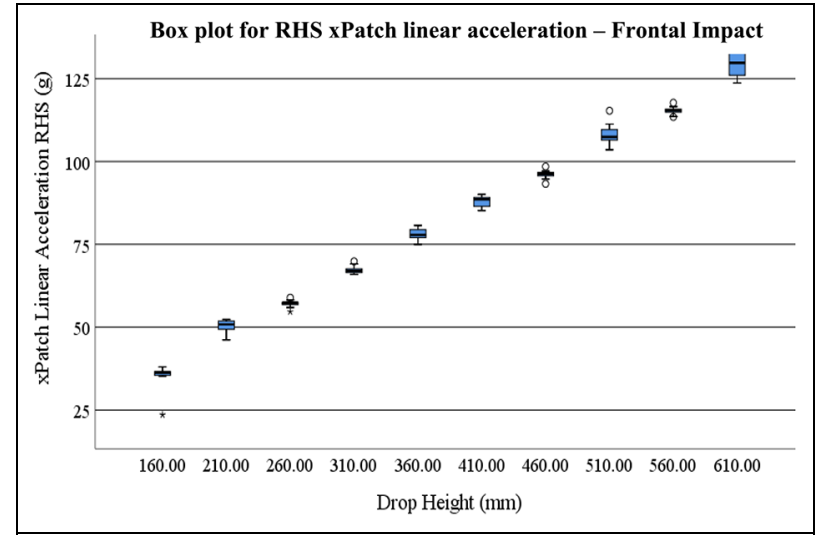

Figure 8. Box plot of median and interquartile range for the linear acceleration recorded by the $x$ Patch on the right-hand side of the headform for each drop height.

$1000 \mathrm{~Hz}$ and angular motion at $800 \mathrm{~Hz} \cdot{ }^{31}$ The low sampling frequency may be a possible cause for the underprediction of results. Unhelmeted impacts require a higher frequency and bandwidth than helmeted sports, due to the shorter duration of the impact. This requirement will have a greater influence on the accuracy of the angular motion data as it has been found that, for dummy helmeted impacts, gyroscopes require bandwidths of 500 and $740 \mathrm{~Hz}$ if numerical differentiation is used to calculate rotational acceleration. ${ }^{31}$ The bandwidth of the gyroscopes in the xPatch may be too low as it has been reported that most of these sensors have a bandwidth of $110 \mathrm{~Hz} .{ }^{31}$ In this study, both the reference and the xPatch rotational acceleration data were computed using a numerical differentiation method. This method amplifies the noise on the signal, and this was particularly apparent on severe impacts where large errors in the rotational acceleration data occurred. In future work, it would be interesting to use a six- or

Table 3. Summary of rotational velocity for frontal impacts.

\begin{tabular}{|c|c|c|c|c|c|c|c|c|c|c|c|}
\hline \multirow{2}{*}{$\begin{array}{l}\text { Drop } \\
\text { height } \\
(\mathrm{mm})\end{array}$} & \multicolumn{3}{|c|}{ Reference sensors } & \multicolumn{4}{|c|}{ xPatch LHS } & \multicolumn{4}{|c|}{ xPatch RHS } \\
\hline & $\begin{array}{l}\text { Average } \\
(\mathrm{rad} / \mathrm{s})\end{array}$ & Std. Dev. & $\begin{array}{l}\text { Standard } \\
\text { error of } \\
\text { mean }\end{array}$ & $\begin{array}{l}\text { Average } \\
(\mathrm{rad} / \mathrm{s})\end{array}$ & Std. Dev. & $\begin{array}{l}\text { Standard } \\
\text { error } \\
\text { of mean }\end{array}$ & \%Error & $\begin{array}{l}\text { Average } \\
(\mathrm{rad} / \mathrm{s})\end{array}$ & Std. Dev. & $\begin{array}{l}\text { Standard } \\
\text { error } \\
\text { of mean }\end{array}$ & \%Error \\
\hline 610 & 25.49 & 3.59 & 1.20 & 30.62 & 0.52 & 0.17 & 20.14 & 27.90 & 0.41 & 0.14 & 9.45 \\
\hline 560 & 25.01 & 2.22 & 0.71 & 28.45 & 0.41 & 0.15 & 13.76 & 26.74 & 0.32 & 0.10 & 6.92 \\
\hline 510 & 23.93 & 2.31 & 0.77 & 27.67 & 0.28 & 0.14 & 15.66 & 25.62 & 0.28 & 0.10 & 7.06 \\
\hline 460 & 23.37 & 1.88 & 0.68 & 26.56 & 0.45 & 0.16 & 13.68 & 24.15 & 0.26 & 0.10 & 3.36 \\
\hline 410 & 21.81 & 2.00 & 0.67 & 25.58 & 0.27 & 0.10 & 17.29 & 23.76 & 0.48 & 0.17 & 8.93 \\
\hline 360 & 20.07 & 1.62 & 0.54 & 19.50 & 2.94 & 0.14 & 2.84 & 23.27 & 3.51 & 0.14 & 15.95 \\
\hline 310 & 16.96 & 1.49 & 0.55 & 22.70 & 0.19 & 0.08 & 33.82 & 21.43 & 0.26 & 0.12 & 26.32 \\
\hline 260 & 16.25 & 1.81 & 0.63 & 20.13 & 0.44 & 0.17 & 23.87 & 20.40 & 0.36 & 0.15 & 25.50 \\
\hline 210 & 15.35 & 1.22 & 0.65 & 18.30 & 0.25 & 0.17 & 19.25 & 18.63 & 0.23 & 0.17 & 21.43 \\
\hline 160 & 14.07 & 1.07 & 0.37 & 15.97 & 0.32 & 0.37 & 13.46 & 16.04 & 0.28 & 0.34 & 13.96 \\
\hline
\end{tabular}

LHS: left-hand side; RHS: right-hand side.

Results for reference sensors and LHS and RHS xPatches are given as well as the percentage errors between the xPatch devices and the reference devices. 
Table 4. Summary of rotational acceleration for frontal impacts.

\begin{tabular}{|c|c|c|c|c|c|c|c|c|c|c|c|}
\hline \multirow{2}{*}{$\begin{array}{l}\text { Drop } \\
\text { height } \\
(\mathrm{mm})\end{array}$} & \multicolumn{3}{|c|}{ Reference Sensors } & \multicolumn{4}{|c|}{ LHS $x$ Patch } & \multicolumn{4}{|c|}{ RHS xPatch } \\
\hline & $\begin{array}{l}\text { Average } \\
\left(\mathrm{rad} / \mathrm{s}^{2}\right)\end{array}$ & $\begin{array}{l}\text { Std. } \\
\text { Dev. }\end{array}$ & $\begin{array}{l}\text { Standard } \\
\text { error of } \\
\text { mean }\end{array}$ & $\begin{array}{l}\text { Average } \\
\left(\mathrm{rad} / \mathrm{s}^{2}\right)\end{array}$ & $\begin{array}{l}\text { Std. } \\
\text { Dev. }\end{array}$ & $\begin{array}{l}\text { Standard } \\
\text { error of } \\
\text { mean }\end{array}$ & \%Error & $\begin{array}{l}\text { Average } \\
\left(\mathrm{rad} / \mathrm{s}^{2}\right)\end{array}$ & Std. Dev. & $\begin{array}{l}\text { Standard } \\
\text { error of } \\
\text { mean }\end{array}$ & \%Error \\
\hline 610 & 7526.5 & 1150.3 & 517.1 & 5896.5 & 290.8 & 96.9 & 21.7 & 5966.0 & 252.5 & 84.2 & 20.7 \\
\hline 560 & 6919.7 & 724.8 & 597.2 & 5806.6 & 161.0 & 62.0 & 16.1 & 5766.0 & 127.1 & 49.7 & 16.7 \\
\hline 510 & 6477.4 & 809.5 & 288.8 & 5751.6 & 95.8 & 33.9 & 11.2 & 5547.5 & 42.5 & 18.8 & 14.4 \\
\hline 460 & 6024.7 & 1311.0 & 796.6 & 5372.6 & 134.3 & 46.1 & 10.8 & 5062.1 & 132.4 & 44.6 & 16.0 \\
\hline 410 & 5780.6 & 1625.0 & 541.7 & 5007.4 & 47.4 & 21.2 & 13.4 & 4693.3 & 121.4 & 40.6 & 18.8 \\
\hline 360 & 5135.8 & 1062.0 & 355.3 & 4502.0 & 6.9 & 46.0 & 12.3 & 4156.1 & 0.3 & 55.1 & 19.1 \\
\hline 310 & 4176.9 & 798.1 & 565.2 & 3996.2 & 91.5 & 42.1 & 4.3 & 3507.5 & 71.8 & 29.3 & 16.0 \\
\hline 260 & 3590.1 & 262.3 & 151.0 & 3465.1 & 61.9 & 28.3 & 3.5 & 2970.1 & 38.9 & 13.1 & 17.3 \\
\hline 210 & 3218.1 & 619.8 & 221.3 & 2682.7 & 31.9 & 16.8 & 16.6 & 2504.9 & 33.8 & 17.3 & 22.2 \\
\hline 160 & 3093.1 & 613.6 & 431.7 & 2079.9 & 30.5 & 62.8 & 32.8 & 2018.0 & 26.5 & 60.0 & 34.8 \\
\hline
\end{tabular}

LHS: left-hand side; RHS: right-hand side.

Results for reference sensors and LHS and RHS xPatches are given as well as the percentage errors between the $x$ Patch devices and the reference devices.

Table 5. Summary of average errors ( $x$ Patch on the LHS and RHS relative to the reference device).

\begin{tabular}{|c|c|c|c|c|c|c|}
\hline & \multicolumn{2}{|c|}{ Frontal impact } & \multicolumn{2}{|l|}{ Side impact } & \multicolumn{2}{|l|}{ Rear impact } \\
\hline & $\begin{array}{l}\text { LHS } \\
\text { xPatch }\end{array}$ & $\begin{array}{l}\text { RHS } \\
\text { xPatch }\end{array}$ & $\begin{array}{l}\text { xPatch on } \\
\text { the side } \\
\text { of impact }\end{array}$ & $\begin{array}{l}\text { xPatch on } \\
\text { the opposite } \\
\text { side }\end{array}$ & $\begin{array}{l}\text { LHS } \\
\text { xPatch }\end{array}$ & $\begin{array}{l}\text { RHS } \\
\text { xPatch }\end{array}$ \\
\hline $\begin{array}{l}\text { Peak linear } \\
\text { acceleration } \\
\text { Rotational } \\
\text { velocity (\%) }\end{array}$ & $\begin{array}{l}+16.9 \% \\
+17.4\end{array}$ & $\begin{array}{l}+23.7 \% \\
+13.9\end{array}$ & $\begin{array}{l}+9 \%>110 g \\
-16 \%<90 \mathrm{~g} \\
+47.5\end{array}$ & $\begin{array}{l}+14.5 \%>110 g \\
-13 \%<90 g \\
+23\end{array}$ & $\begin{array}{l}+5 \%>110 g \\
-30 \%<90 g \\
+20\end{array}$ & $\begin{array}{l}+20 \%>110 g \\
-30 \%<90 g \\
+33\end{array}$ \\
\hline $\begin{array}{l}\text { Peak rotational } \\
\text { acceleration (\%) }\end{array}$ & -14.3 & -19.6 & +46.5 & +52 & -57 & +12 \\
\hline
\end{tabular}

LHS: left-hand side; RHS: right-hand side.

nine-accelerometer array as used in some other stud$\operatorname{ies}^{33}$ to eliminate the requirement for numerical differentiation.

This study demonstrates the usefulness of the xPatch for identifying and recording impacts, as all of the impacts tested were recorded, that is, no false positives or negatives. However, it must be noted that our study had a controlled setup and is unlike in-field testing; the study by Press and Rowson ${ }^{30}$ which resulted in a positive head impact prediction rate of $16.3 \%$ questions the reliability of the sensor on the field and highlights the need for video confirmation of all impacts. Recording all head impacts accurately, without either over- or underprediction, is important in studies of player welfare. $^{34,35}$ To date, the xPatch sensor has been used to collect cumulative data in helmeted ${ }^{31}$ and unhelmeted sports. ${ }^{23}$ King et al. ${ }^{23}$ utilised the xPatch to measure the magnitude, frequency and location of head impacts sustained by under 9s Rugby Union players over the course of four consecutive matches. A study indicating the usefulness of such sensors in regard to player's welfare was undertaken by Swartz et al. ${ }^{36}$ They conducted a study over the course of an American Football season and used the xPatch with two separate cohorts of players. The objective of the study was to analyse the head impacts of a group who practised unhelmeted drills against those who practised with helmets. It was determined that there was a $28 \%$ reduction in head impact frequency recorded by the group that did not use helmets during practices.

Accurately recording the occurrence, magnitude and direction of all impacts is critical in any investigation of head impacts. This study has highlighted that the results from the xPatch device must be treated with caution: frontal impacts are recorded with reasonable accuracy (up to 24\%), but rotational velocity and acceleration results from side and rear impacts may have large errors.

\section{Conclusion}

This study has shown that the xPatch performs reasonably well in terms of linear acceleration but has highlighted that the rotational velocity and acceleration 
measurements recorded by the xPatch have high levels of error and therefore need to be used with caution. This study also found that there is an issue using differentiation to calculate rotational acceleration unless the sampling frequency and bandwidth are suitable. To improve the rotational acceleration measurements, either a higher sampling rate or an array of accelerometers that allows the rotational acceleration to be calculated without differentiation must be used.

\section{Declaration of conflicting interests}

The author(s) declared no potential conflicts of interest with respect to the research, authorship and/or publication of this article.

\section{Funding}

The author(s) disclosed receipt of the following financial support for the research, authorship, and/or publication of this article: This work was funded by the President's Award from the Institute of Technology Tallaght, Dublin.

\section{ORCID iD}

Stephen Tiernan (D) https://orcid.org/0000-0002-06587557

\section{References}

1. Langlois JA, Rutland-Brown W and Wald MM. The epidemiology and impact of traumatic brain injury: a brief overview. J Head Trauma Rehabil 2006; 21(5): 375-378.

2. Elliott MR, Margulies SS, Maltese MR, et al. Accounting for sampling variability, injury under-reporting, and sensor error in concussion injury risk curves. $J$ Biomech 2015; 48(12): 3059-3065.

3. Sye G, Sullivan SJ, McCrory P, et al. High school rugby players' understanding of concussion and return to play guidelines. Br J Sports Med 2006; 40(12): 1003-1005.

4. McCrory P, Meeuwisse W, Dvorak J, et al. Consensus statement on concussion in sport - the 5th international conference on concussion in sport held in Berlin, October 2016. Br J Sports Med 2017; 51: 838-847.

5. Broglio SP, Schnebel B, Sosnoff JJ, et al. The biomechanical properties of concussions in high school football. Med Sci Sports Exerc 2010; 42(11): 2064-2071.

6. Abel JM, Gennarelli T and Segawa H. Incidence and severity of cerebral concussion in the rhesus monkey following sagittal plane angular acceleration. SAE technical paper 780886, 1978.

7. Bayly PV, Cohen TS, Leister EP, et al. Deformation of the human brain induced by mild acceleration. $J$ Neurotrauma 2005; 22(8): 845-856.

8. Hardy WN, Mason MJ, Foster CD, et al. A study of the response of the human cadaver head to impact. Stapp Car Crash J 2007; 51: 17-80.

9. Post A and Hoshizaki TB. Rotational acceleration, brain tissue strain, and the relationship to concussion. $J$ Biomech Eng 2015; 137(3): 030801.
10. King AI, Yang KH, Zhang L, et al. Is head injury caused by linear or angular acceleration. In: Proceedings of the 2003 IRCOBI conference, Lisbon, 25-26 September 2003, pp.1-12. Zurich: IRCOBI.

11. Takhounts EG, Craig MJ, Moorhouse K, et al. Development of brain injury criteria (BrIC). Stapp Car Crash J 2013; 57: 243-266.

12. Zhang L, Yang KH and King AI. Comparison of brain responses between frontal and lateral impacts by finite element modeling. $J$ Neurotrauma 2001; 18(1): 21-30.

13. Zhang L, Yang KH and King AI. A proposed injury threshold for mild traumatic brain injury. J Biomech Eng 2004; 126(2): 226-236.

14. Crisco JJ, Chu JJ and Greenwald RM. An algorithm for estimating acceleration magnitude and impact location using multiple nonorthogonal single-axis accelerometers. Journal of Biomechanical Engineering 2014; 126(6): 849-854.

15. Hanlon E and Bir C. Validation of a wireless head acceleration measurement system for use in soccer play. $J$ Appl Biomech 2010; 26(4): 424-431.

16. Jadischke R, Viano DC, Dau N, et al. On the accuracy of the Head Impact Telemetry (HIT) System used in football helmets. J Biomech 2013; 46(13): 2310-2315.

17. Duma SM, Manoogian SJ, Bussone WR, et al. Analysis of real-time head accelerations in collegiate football players. Clin J Sport Med 2005; 15(1): 3-8.

18. Rowson S, Duma SM, Beckwith JG, et al. Rotational head kinematics in football impacts: an injury risk function for concussion. Ann Biomed Eng 2012; 40(1): 1-13.

19. Beckwith JG, Chu JJ and Greenwald RM. Validation of a noninvasive system for measuring head acceleration for use during boxing competition. J Appl Biomech 2007; 23(3): 238-244.

20. Caccese JB, Lamond LC, Buckley TA, et al. Reducing purposeful headers from goal kicks and punts may reduce cumulative exposure to head acceleration. Res Sports Med 2016; 24(4): 407-415.

21. Hanlon EM and Bir CA. Real-time head acceleration measurement in girls' youth soccer. Med Sci Sports Exerc 2012; 44(6): 1102-1108.

22. Naunheim RS, Standeven J, Richter C, et al. Comparison of impact data in hockey, football, and soccer. $J$ Trauma 2000; 48(5): 938-941.

23. King D, Hume $\mathrm{P}$, Gissane $\mathrm{C}$, et al. Head impacts in a junior rugby league team measured with a wireless head impact sensor: an exploratory analysis. J Neurosurg Pediatr 2017; 19(1): 13-23.

24. Higgins M, Halstead PD, Snyder-Mackler L, et al. Measurement of impact acceleration: mouthpiece accelerometer versus helmet accelerometer. $J$ Athl Train 2007; 42(1): 5-10.

25. Cummiskey B, Schiffmiller D, Talavage TM, et al. Reliability and accuracy of helmet-mounted and headmounted devices used to measure head accelerations. Proc IMechE, Part P: J Sports Engineering and Technology 2017; 231(2): 144-153.

26. Wood GW, Panzer MB, Bass CR, et al. Viscoelastic properties of Hybrid III head skin. SAE Int J Mater Manuf 2010; 3: 186-193.

27. Schussler E, Stark D, Bolte JH, et al. Comparison of a head mounted impact measurement device to the Hybrid III anthropomorphic testing device in a controlled laboratory setting. Int J Sports Phys Ther 2017; 12(4): 592-600. 
28. Nevins D, Smith L and Kensrud J. Laboratory evaluation of wireless head impact sensor. Procedia Engineer 2015; 112: 175-179.

29. National Instruments, LabVIEW. Using Fast Fourier Transforms and power spectra in LabVIEW, 2017, http:// www.ni.com/white-paper/4541/en/

30. Press JN and Rowson S. Quantifying head impact exposure in collegiate women's soccer. Clin J Sport Med 2017; 27(2): 104-110.

31. Wu LC, Laksari K, Kuo C, et al. Bandwidth and sample rate requirements for wearable head impact sensors. $J$ Biomech 2016; 49: 2918-2924.

32. Siegmund GP, Guskiewicz KM, Marshall SW, et al. Laboratory validation of two wearable sensor systems for measuring head impact severity in football players. Ann Biomed Eng 2016; 44(4): 1257-1274.
33. Davenport EM, Whitlow CT, Urban JE, et al. Abnormal white matter integrity related to head impact exposure in a season of high school varsity football. $J$ Neurotrauma 2014; 31(19): 1617-1624.

34. Guskiewicz KM, McCrea M, Marshall SW, et al. Cumulative effects associated with recurrent concussion in collegiate football players: the NCAA Concussion Study. JAMA 2003; 290(19): 2549-2555.

35. McCuen E, Svaldi D, Breedlove K, et al. Collegiate women's soccer players suffer greater cumulative head impacts than their high school counterparts. $J$ Biomech 2015; 48(13): 3720-3723.

36. Swartz EE, Broglio SP, Cook SB, et al. Early results of a helmetless-tackling intervention to decrease head impacts in football players. J Athl Train 2015; 50(12): 1219-1222. 